Table 1. Data on incident SpA patients between 2010-14, divided into two groups depending on whether bDMARDs were introduced (group B) or not (group A). Pain medication and DMARD use during the whole first year after the ID are shown.

\begin{tabular}{lccc}
\hline & $\begin{array}{c}\text { Group A } \\
\text { N=2741 }\end{array}$ & $\begin{array}{c}\text { Group B } \\
\text { N=836 }\end{array}$ & p-value \\
\hline Age, mean (SD) & $39(13)$ & $38(11)$ & 0.16 \\
Proportion of females, \% & 53 & 49 & 0.048 \\
Pain medication,\% & & & \\
Paracetamol & 21.1 & 24.9 & 0.020 \\
NSAID & 71.9 & 78.5 & $<0.001$ \\
Opioid & 18.2 & 33.0 & $<0.001$ \\
DMARDs & & & \\
None & 3.6 & 0.2 & \\
Methotrexate & 29.9 & 53.8 & $<0.001$ \\
Sulphasalazine & 84.5 & 78.6 & $<0.001$ \\
Prednisolone & 33.8 & 47.0 & $<0.001$ \\
Other csDMARDs & 6.5 & 9.8 & $<0.001$ \\
BDMARDs & 0 & 58.0 &.. \\
\hline
\end{tabular}

Disclosure of Interests: Paula Muilu Grant/research support from: I have received a Congress trip from UCB Pharma and a Congress trip from MSD Finland outside the submitted work, Vappu Rantalaiho Grant/ research support from: Dr. Rantalaiho has received a congress trip from Pfizer and a congress trip from Celegen outside the submitted work., Speakers bureau: Dr Rantalaiho reports a speaker's honorarium from Pfizer., Hannu Kautiainen: None declared, Lauri Virta: None declared, Kari Puolakka: None declared

DOI: 10.1136/annrheumdis-2019-eular.1138

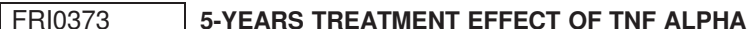 INHIBITOR IN EARLY AXIAL SPONDYLOARTHRITIS AND ASSOCIATED FACTORS: AN INVERSE PROBABILITY WEIGHTING ANALYSIS OF THE DESIR COHORT}

Marion Pons ${ }^{1,2}$, Sylvie Chevret ${ }^{2}$, Karine Briot ${ }^{1,2}$, Maria-Antonietta D'agostino ${ }^{3}$, Christian Roux ${ }^{1,2}$, Maxime Dougados ${ }^{1,2}$, Anna Moltó ${ }^{1,2} .{ }^{1}$ University Paris Descartes, Cochin Hospital, Rheumatology, Paris, France; ${ }^{2}$ INSERM U-1153, CRESS Paris-Sorbonne, Paris, France; ${ }^{3}$ Ambroise-Paré Hospital, Rheumatology, Boulogne-Billancourt, France

Background: Only scarce data is available on the long-term treatment effect in a real-life setting (i.e. effectiveness) of TNFi in early axial SpA forms and its predisposing associated factors; furthermore, unbiased evaluation of treatment effect in non-randomized clinical trials is challenging, and new methods have been developed to overcome prescription bias. Objectives: a) to estimate the probability to initiate a TNFi over 5 years of follow up in real life setting using novel statistical methods to overcome prescription bias; b) to determine the long-term effectiveness of first TNFi and its predictive factors.

Methods: Observational prospective French cohort (DESIR) with 5 years of follow-up, including 708 TNFi-naïve patients early axial spondyloarthritis. Study visits were scheduled every 6 months in the first two years of follow up then yearly up to 5 years. Treatment (TNFi or other) was at the discretion of the treating rheumatologist's. The probability to initiate a TNFi was estimated by the Kaplan Meier Method, assuming non informative dropouts. Effectiveness of the first TNFi was defined as the probability to reach an ASAS40 response in both groups (TNFi vs. any other treatment) after at least 10 months of exposure. To evaluate treatment effect and overcome prescription bias repeatedly occurring over time, we have applied an iterative method based on inverse propensity score (PS) weighting using a marginal structural model, that allows the integration of the repeated weights derived from the propensity score at each visit (i.e. the probability to receive the treatment at each visit). The structural model used for this analysis was a PS-weighted cox regression, to estimate the probability to present an ASAS40 response after at least 10 months of treatment. Factors predicting first TNFi effectiveness, were explored by Cox (univariate and then multivariate) regression models.

Results: Of the 708 patients included in the analysis, 258 patients initiated a first TNFi during the first five years of follow up. The probability to initiate a TNFi treatment was $41.3 \%[95 \% \mathrm{Cl} 37.2-45.1]$. Among the 258 patients who received a first TNFi, $163(63.2 \%)$ were exposed for at least 10 months. On the original data, ASAS40 response was observed in $50 / 163(30.7 \%)$ vs. $58 / 450(12.9 \%)$ patients from the TNFi and usual care groups, respectively. The likelihood of an ASAS40 response was greater in the TNFi exposed group $(\mathrm{HR}=3.3[95 \% \mathrm{Cl} 2.9-3.8], \mathrm{p}<0.0001)$. Male gender $(\mathrm{HR}=1.5[95 \% \mathrm{Cl} 1.1-2.1])$, $\mathrm{HLAB} 27+(\mathrm{HR}=1.4[95 \% \mathrm{Cl} 1.1-$ 2.0]) and the presence of at least one objective sign of inflammation
(MRI or CRP) or structural damage (radiographic sacroiliitis) ( $\mathrm{HR}=1.7$ [95\% $\mathrm{Cl} 1.2-2.4])$ were jointly predictive of an improved outcome.

Conclusion: Our study, applying novel statistical techniques to overcome prescription bias, confirms the 5-year effectiveness of TNF alpha inhibitors (TNFi) in patients with early axial Spondyloarthritis $(\operatorname{axSpA})$, and we confirm that male gender, with HLAB7 positive and the presence of at least one objective sign of inflammation or structural damage are more frequently associated with such effectiveness.

Disclosure of Interests: Marion Pons: None declared, Sylvie Chevret: None declared, Karine Briot Consultant for: Karine Briot has received consultancy honoraria and conference fees from UCB, Amgen, Lilly and MSD, Maria-Antonietta d'Agostino: None declared, Christian Roux Grant/ research support from: Alexion, Amgen, UCB, maxime dougados Grant/ research support from: Eli Lilly and Company, Pfizer, AbbVie, and UCB Pharma, Consultant for: Eli Lilly and Company, Pfizer, AbbVie, and UCB Pharma, Anna Moltó: None declared DOI: 10.1136/annrheumdis-2019-eular.3518

\section{FRI0374 FACTOR INHIBITORS AND ITS ASSOCIATED FACTORS IN PATIENTS WITH ANKYLOSING SPONDYLITIS: RESULT FROM KOREAN NATIONAL HEALTH INSURANCE DATA}

Bon San Koo ${ }^{1}$, Yu-Cheol Lim², Min-Young Lee ${ }^{3}$, Ja-Young Jeon ${ }^{4}$, HyunJeong Yoo ${ }^{4}$, In-Sun $\mathrm{Oh}^{2}$, Ju-Young Shin ${ }^{2}$, Eui-Kyung Lee ${ }^{2}$, Tae-Hwan Kim ${ }^{5}$. ${ }^{1}$ Inje University Seoul Paik Hospital, Inje University College of Medicine, Department of Internal Medicine, Seoul, Korea, Rep. of (South Korea); ${ }^{2}$ Sungkyunkwan University, School of Pharmacy, Suwon, Korea, Rep. of (South Korea); ${ }^{3}$ VIAplus, Siheung, Korea, Rep. of (South Korea); ${ }^{4}$ Pfizer Inc, Seoul, Korea, Rep. of (South Korea); ${ }^{5}$ Hanyang University Hospital for Rheumatic Diseases, Department of Rheumatology, Seoul, Korea, Rep. of (South Korea)

Background: Tumor necrosis factor inhibitors (TNFi) are effective in patients who do not respond to non-steroidal anti-inflammatory drugs, or disease modifying anti-rheumatic drugs, and have been widely used in patients with ankylosing spondylitis (AS). However, there is some evidence that treatment with TNFi can increase the risk of infection in patients with AS.

Objectives: The aim of this study was to investigate the risk of infection in patients with AS treated with TNFi.

Methods: Data was obtained from insurance claims database of the Health Insurance Review \& Assessment Service (HIRA) in South Korea Patients who have been prescribed a TNFi such as etanercept (ETN), adalimumab (ADA), golimumab (GLM), and infliximab (IFX) to treat AS from 1 July 2012 to 30 June 2017 were enrolled. We evaluated the incidence rate $(\mathrm{IR})$ and hazard ratio $(\mathrm{HR})$ of serious infections including pneumonia, tuberculosis, and herpes zoster in each TNFi treatment group by using cox proportional hazard model. We further analyzed the HR of infection by sex.

Results: A total of 2,515 patients were included in the study, and they were prescribed ETN ( $n=528)$, ADA $(n=914)$, GLM $(n=628)$, or IFX $(n=445)$. The IRs of serious infection were 1668.63, 1489.88, 1457.58, and 1399.16 per 1,000 person years (pys) in ETN, ADA, GLM, and IFX treated groups, respectively. There was no significant difference in HR of serious infection between the TNFi groups. In the subgroup analysis of major infections, there was no difference in the HR of pneumonia between TNFi groups. However, the HR of tuberculosis with IFX group was significantly higher than that with ETN (adjusted $\mathrm{HR} 8.95,95 \% \mathrm{Cl}$ : 1.12-71.4). In herpes zoster infection, there was no difference between TNFi groups in all patients, but the adjusted HRs significantly increased with GLM (adjusted HR 15.40, 95\% Cl: 1.64-144.34) and IFX (adjusted HR 10.02, $95 \% \mathrm{Cl}: 1.12-89.9)$ treatment as compared to ETN in female patients.

Conclusion: Patients receiving IFX had a higher risk of contracting tuberculosis than those receiving ETN. Moreover, the risk of herpes zoster was higher in female patients treated with GLM and IFX than in those treated with ETN in Korea.

\section{REFERENCES}

[1] Kim JA, Yoon S, Kim LY, Kim DS. Towards Actualizing the Value Potential of Korea Health Insurance Review and Assessment (HIRA) Data as a Resource for Health Research: Strengths, Limitations, Applications, and Strategies for Optimal Use of HIRA Data. J Korean Med Sci 2017;32:718728.

[2] Fouque-Aubert A, Jette-Paulin L, Combescure C, et al. Serious infections in patients with ankylosing spondylitis with and without TNF blockers: a 
systematic review and meta-analysis of randomised placebo-controlled trials. Ann Rheum Dis 2010;69:1756-1761.

Acknowledgement: Study sponsored by Pfizer Inc. Disclosure of Interests: Bon San Koo Grant/research support from: Pfizer, Yu-Cheol Lim: None declared, Min-Young Lee: None declared, Ja-Young Jeon Employee of: Pfizer, Hyun-Jeong Yoo Employee of: Pfizer, In-Sun Oh: None declared, Ju-Young Shin: None declared, Eui-Kyung Lee Grant/ research support from: Pfizer, Tae-hwan Kim: None declared DOI: 10.1136/annrheumdis-2019-eular.3197

\section{FRI0375 $\quad$ SITE-SPECIFIC EFFECTIVENESS OF TNF INHIBITORS FOR ENTHESITIS IN DMARD-NAIVE PATIENTS WITH AXIAL SPONDYLOARTHRITIS}

Thomas Huegle ${ }^{1}$, Burkhard Moeller ${ }^{2}$, Adrian Ciurea ${ }^{3}$, Michael Nissen ${ }^{4}$, Patrick Zueger ${ }^{5}$, Martin Schulz ${ }^{6}$, Fabiana Ganz ${ }^{6}$, Almut Scherer ${ }^{7}$, Eleftherios Papagiannoulis ${ }^{7} .{ }^{1}$ Lausanne University Hospital (CHUV), Lausanne, Switzerland; ${ }^{2}$ University Hospital of Bern, Bern, Switzerland; ${ }^{3}$ University Hospital Zurich, Zurich, Switzerland; ${ }^{4}$ Geneva University Hospital, Geneva, Switzerland; ${ }^{5}$ AbbVie Inc., North Chicago, United States of America; ${ }^{6}$ AbbVie AG, Baar, Switzerland; ${ }^{7}$ Swiss Clinical Quality Management in Rheumatic Diseases Foundation, Zurich, Switzerland

Background: Enthesitis is a hallmark of spondyloarthritis (SpA), with substantial impact on quality of life. Although pathophysiological mechanisms of enthesitis may include both mechanical and autoimmune features, improvements upon initiation of TNF-inhibitors (TNFi) across individual enthesitis sites have not been reported in real-world patients with axial spondyloarthritis (axSpA)

Objectives: To investigate the effectiveness of TNFi in axSpA patients without prior DMARD treatment at specific enthesitis sites, including spine thoracic cage, Achilles tendon and the plantar fascia.

Methods: This was a retrospective cohort study using the Swiss Clinical Quality Management in Rheumatic Diseases (SCQM) registry. AxSpA patients initiating TNFi without previous DMARD (biologic or conventional synthetic DMARD [csDMARD]) use and with available Maastricht Ankylosing Spondylitis Enthesitis Score, modified to include the plantar fascia, (MASES) at start of treatment ('baseline') and after 6 months $( \pm 3$ months) of follow up were included. Presence of enthesitis was defined as at least 1 inflamed enthesis. Among patients with any enthesitis present at baseline, the number of patients with enthesitis at each MASES site was assessed at baseline and the 6 month follow up. Fisher's exact test was used to assess significant enthesitis resolution at each enthesitis site between baseline and 6-month follow up. The HolmBonferroni method was used for multiplicity correction of $p$-values.

Results: 781 DMARD-naive patients with axSpA who initiated TNFi were identified. At baseline, patients (57\% male) were a median of 40 (interquartile range $[[Q R])=31-50$ ) years of age with a median disease duration of $9(\mathrm{IQR}=3-18)$ years and median Ankylosing Spondylitis Disease Activity Score (ASDAS-CRP) of 3.4 (IQR = 2.8-3.9) at treatment initiation. A subgroup of $160 \mathrm{TNFi}$ patients had active enthesitis at baseline (MASES: mean $=4.14$, standard deviation $[\mathrm{sd}]=2.87$ ) and a 6-month follow-up visit with MASES available (MASES: mean $=2.07$, $\mathrm{sd}=2.82$ ), with a mean MASES reduction at the follow-up visit of 2.07 (sd = 3.06). At the 6-month follow up, complete enthesitis resolution was observed for $72(45.0 \%)$ of patients. Enthesitis resolution was most frequent at the following sites: the costochondral sternum, the costochondral joint, the lumbar vertebra, the pelvic crest, and spina iliaca posterior (Figure 1) Limited resolution of enthesitis was observed in the spina iliaca anterior, plantar fascia, and the Achilles tendon.

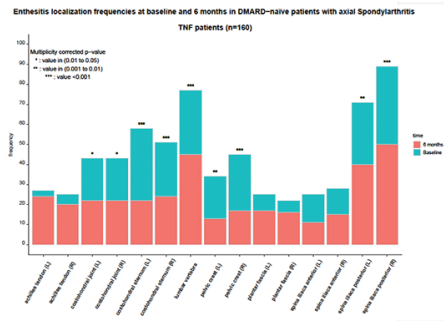

Conclusion: Our results suggest that for real-world DMARD-naïve axSpA patients, TNFi are generally effective for resolving enthesitis. Significant resolution was observed for enthesitis of the spine and thoracic cage though resolution was more limited for plantar fascia or Achilles tendon enthesitis. Lower limb entheses are more prone to mechanical strain and may therefore require alternative or more prolonged therapy.

Acknowledgement: This study was funded by AbbVie Inc. All authors were involved in the study design, review, data interpretation and approval of the abstract.

Disclosure of Interests: Thomas Huegle Grant/research support from: AbbVie, Lilly, Novartis and Pfizer, Speakers bureau: AbbVie, Lilly, Novartis and Pfizer, Burkhard Moeller Consultant for: Swissmedic Human Medicines Expert Committee Member (regulatory agency), Adrian Ciurea Consultant for: AbbVie, Celgene, Janssen-Cilag, MSD, Eli Lilly, Novartis, Pfizer, UCB, Speakers bureau: Abbvie, Celgene, Janssen-Cilag, MSD, Eli Lilly, Novartis, Pfizer, UCB, Michael Nissen Consultant for: AbbVie, Lilly Novartis, and Pfizer, Patrick Zueger Shareholder of: AbbVie, Employee of AbbVie, Martin Schulz Shareholder of: AbbVie, Employee of: AbbVie Fabiana Ganz Shareholder of: AbbVie, Employee of: AbbVie, Almut Scherer Grant/research support from: Almut Scherer is an employee of SCQM, which receives funding from AbbVie, Celgene, iQONE, Lilly, MSD, Novartis, Pfizer, Roche, Sandoz, Sanofi Genzyme, and UCB., Consultan for: Consultant for Pfizer, MSD, and AbbVie, Eleftherios Papagiannoulis: None declared

DOI: 10.1136/annrheumdis-2019-eular.5819

\section{FRI0376 DIFFERENCES IN PHYSICAL ACTIVITY BETWEEN AXIAL SPONDYLOARTHRITIS PATIENTS WITH AND WITHOUT PHYSICAL THERAPY}

Bas Hilberdink $^{1}$, Florus van der Giesen ${ }^{2}$, Thea Vliet Vlieland ${ }^{1}$, Floris A. van Gaalen $^{2}$, Karel Ronday ${ }^{3}$, Andreas Peeters ${ }^{4}$, Salima van Weely ${ }^{1}{ }^{1}$ Leiden University Medical Center, Orthopaedics, Rehabilitation and Physical Therapy, Leiden, Netherlands; ${ }^{2}$ Leiden University Medical Center, Rheumatology, Leiden, Netherlands: ${ }^{3}$ Haga Hospital, The Hague, Netherlands; ${ }^{4}$ Reinier de Graaf Gasthuis, Delft, Netherlands

Background: Physical activity (PA) according to public health guidelines is effective and safe for people with rheumatic and musculoskeletal diseases, including axial spondyloarthritis ( $\mathrm{axSpA})$, and should be promoted by healthcare providers. ${ }^{1}$ In axSpA, in particular high intensity aerobic PA is beneficial, yet this was found to be incompletely implemented in physical therapy programs. $^{2}$ Studies describing aerobic PA in axSpA patients with and without physical therapy are lacking.

Objectives: To describe the amount, frequency and intensity of aerobic PA in axSpA patients with and without physical therapy treatment.

Methods: A survey, which included questions on patient characteristics, current physical therapy use (individual or group), PA (Short QUestionnaire to ASess Health-enhancing PA (SQUASH)) and health status (Assessment of Spondyloarthritis International Society Health Index (ASAS HI)), was sent by postal-mail to 458 axSpA patients registered in three hospitals in the Netherlands. From the SQUASH, besides amount (minutes/week) of all PA and meeting the PA guideline ( $\geq 30$ minutes $\geq$ moderate PA on $\geq 5$ days/ week; yes/no), also the amount and frequency (sessions/week) of moderate and vigorous intensity aerobic PA during commuting and leisure (including sports) were extracted. Differences in PA behaviour between patients with and without current physical therapy were analyzed with the Mann-Whitney $\mathrm{U}$ or Chi-square test, where appropriate.

Results: The questionnaire was returned by 206 axSpA patients (response rate: 45\%) of whom 200 completed the SQUASH correctly Overall, $64 \%$ met the PA guideline. Half of the patients were using physical therapy ( $n=99 ; 77$ individual, 11 group and 11 both); these patients had a significantly longer disease duration. Regarding overall PA, there were no differences in the total amount and the proportion meeting the guideline between patients with and without physical therapy. For moder ate intensity aerobic PA, both the amount and frequency were significantly greater in the group with physical therapy, whereas for vigorous intensity aerobic PA there were no differences between the groups (Table 1).

Conclusion: More than half of people with axSpA were physically active according to public health PA guidelines. People using physical therapy engaged in significantly more moderate intensity, but not high intensity aerobic PA than those without physical therapy. These results indicate that high intensity aerobic PA should be more intensively advocated and implemented, also in physical therapy treatment.

\section{REFERENCES:}

[1] Rausch Osthoff, et al. Ann Rheum Dis. 2018;77:1251-1260.

[2] Niedermann, et al. Arthritis Care Res. 2018. Doi: :10.1002/acr.23705 